\title{
ECONOMIA E POLÍTICA DOS DIREITOS CULTURAIS NA ORDEM INTERNACIONAL
}

\section{ECONOMY AND POLITICS OF CULTURAL RIGHTS IN THE INTERNATIONAL ORDER}

\author{
Lucas Fucci Amato*
}

\begin{abstract}
RESUMO
O artigo discute as restrições impostas pela economia e pela política ao desenho normativo dos direitos culturais na ordem jurídica internacional. O eixo da análise é a Convenção da UNESCO sobre Proteção e Promoção da Diversidade das Expressões Culturais (2005), mas também se destacam as condições problemáticas de inserção dos direitos culturais nos sistemas universais e regionais de direitos humanos. Finalmente, foca-se o status dos direitos culturais em relação à propriedade intelectual e ao regime da OMC. O trabalho segue uma linha de análise da teoria dos sistemas para pensar as relações entre direito, política e economia.
\end{abstract}

\section{PALAVRAS-CHAVE}

Direitos culturais. Direito e cultura. Livre-comércio e direitos humanos.

\begin{abstract}
The paper discusses the restrictions imposed by economy and politics to the normative design of cultural rights in the international legal order. The axis of this analysis is the UNESCO Convention on the Protection and Promotion of the Diversity of Cultural Expressions (2005), but we also detach the problematic conditions of the insertion of cultural rights in the universal and regional systems of human rights. Finally, we focus on the status of cultural rights in relation to intellectual property and to the WTO regime. The work follows a line of analysis from systems theory in order to think the relations between law, politics and economy.
\end{abstract}

\section{KEYWORDS}

Cultural rights. Law and culture. Free trade and human rights.

\footnotetext{
* Doutorando em Filosofia e Teoria Geral do Direito e Bacharel pela Faculdade de Direito da Universidade de São Paulo (USP, São Paulo, SP, Brasil). Visiting Researcher na Harvard Law School. Bolsista da Fundação de Amparo à Pesquisa do Estado de São Paulo (FAPESP).E-mail: lucas.amato@usp.br
} 


\section{INTRODUÇÃO}

Este artigo pretende oferecer uma análise da inserção dos direitos culturais (ou do direito à cultura) no plano da normatividade internacional ${ }^{1}$, enfatizando as restrições que a política e a economia impõem à juridicidade desses direitos. Isso significa que o desenho normativo, os sucessivos processos de interpretação e as estratégias de concretização dos direitos culturais são obstaculizados por restrições que os valores e interesses políticos e econômicos adjacentes fazem prevalecer sobre os valores e interesses proclamados pelos textos normativos internacionais. Tal fenômeno é exemplificado pela Convenção da Organização das Nações Unidas para a Educação, a Ciência e a Cultura (UNESCO) sobre a Proteção e Promoção da Diversidade das Expressões Culturais (2005), pelas construções interpretativas e limites institucionais dos sistemas universal e regionais de direitos humanos e pela difícil inserção dos direitos humanos no direito do comércio internacional.

A análise vale-se especialmente da teoria dos sistemas sociais. Luhmann (2002, p. 61) analisou os direitos fundamentais como mecanismos de "manutenção de uma ordem social diferenciada”, a qual, à época do surgimento dos primeiros direitos "humanos”, “fundamentais” ou congêneres - os direitos [liberais] civis e políticos -, sofria a principal ameaça por parte do expansionismo do sistema político sobre os demais sistemas (politização). Ao notar (LUHMANN, 2002, p. 76) que, com o crescimento [do potencial] da diferenciação funcional, também crescem as interdependências dos sistemas sociais, de modo que uma mesma comunicação, expectativa ou instituição pode servir a diferentes funções em diferentes sistemas, Luhmann (2002, p. 294) considerou que a própria interdependência dos sistemas sociais “torna necessária a institucionalização de uma pluralidade de direitos fundamentais”.

Diante do diagnóstico de que a diferenciação funcional, embora tenha um potencial de inclusão limitado (LUHMANN, 2007, p. 502), é essencial para se evitar a exclusão em cadeia e em massa das pessoas em relação aos diversos sistemas sociais (LUHMANN, 2007, p. 490-502), e de que tal forma de diferenciação não se encontra satisfatoriamente realizada em muitos segmentos da sociedade mundial, cabe adicionar à ideia de "manutenção de uma ordem social diferenciada” a noção de promoção dessa diferenciação - promoção para a qual o direito tem possibilidades (ainda que operativamente limitadas) de contribuir na medida em que irrite os demais sistemas sociais, i.e., pela afirmação de uma expectativa contrafática nesse sentido. Ademais, o expansionismo do

\footnotetext{
${ }^{1}$ Não se pretende aqui oferecer uma ampla descrição da normatividade internacional sobre o tema dos direitos culturais, mas sim uma análise de certos aspectos políticos e econômicos julgados relevantes. Para um elenco panorâmico dessa normatividade, cf. AMATO, 2012.
} 
sistema econômico também adverte no sentido da moldagem institucional de direitos humanos ou fundamentais voltados ao âmbito privado (por exemplo, pretensões dirigidas contra organizações empresariais) (AMATO, 2014).

O sentido de “manutenção de uma ordem diferenciada” (LUHMANN, 2007, p. 538-615) pode ser interpretado como vinculado não só à diferenciação interna da sociedade (funcional, segmentária, hierárquica, centro-periferia) - em um sentido de complexificação e diversificação, antes que de conservação ou simplificação -, mas também à diferenciação da sociedade em relação ao ser humano, dela excluído como indivíduo (acoplamento de um sistema orgânico a um sistema psíquico) e nela incluído como pessoa (referência e centro de imputação de comunicações) (LUHMANN, 2007, p. 78, 190, 377).

Assim, Teubner (2006) interpreta os direitos humanos como garantias da integridade dos corpos e mentes humanos contra sua instrumentalização direta pelos sistemas funcionais da sociedade. A proteção contra essa instrumentalização decorreria argumentativamente da dignidade da pessoa humana, ressignificada pela teoria dos sistemas, mas já tradicionalmente reconhecida como fundamento dos direitos humanos (notadamente na tradição germânica), principalmente a partir da ideia kantiana do ser humano como um “fim em si mesmo” (KANT, 2003, p. 73-74).

\section{A CONVENÇÃO DA UNESCO SOBRE A PROTEÇÃO E PROMOÇÃO DA DIVERSIDADE DAS EXPRESSÕES CULTURAIS}

A ideia de diversidade cultural, que embasa a Convenção da UNESCO de 2005, é relevante para um entendimento dos direitos humanos culturais dentro de um paradigma sociológico que compreende o funcionamento da sociedade (pela comunicação) a partir da diferenciação de sistemas funcionais (política, direito, economia, arte, educação, religião) e da pretensão expansiva de cada sistema, da pluralidade de discursos no interior de cada sistema e âmbito de comunicação e do dissenso (LUHMANN, 2007, p. 4) que se manifesta na diversidade de valores e interesses dignificados simbolicamente como expectativas juridicamente reconhecidas, isto é, com a pretensão de generalização (LUHMANN, 2007, p. 4; NEVES, 2008, p. 151).

Pode-se entender como expectativa vinculada aos direitos humanos fundamentais culturais a equalização ou minoração das disparidades de comunicabilidade das comunidades culturais e das pessoas, isto é, o ideário de um maior equilíbrio da participação das diferentes pessoas e coletividades na formação do âmbito cultural e de um acesso mais amplo a essa diversidade de criações. Tal noção ganha uma base normativa considerável com a Convenção da UNESCO sobre a Proteção e Promoção da Diversidade das Expressões Culturais, tanto no plano dos princípios que 
adota quanto na referência às respectivas medidas que prevê. Os princípios mais destacáveis adotados pela Convenção são o da "igual dignidade e do respeito por todas as culturas” (art. 2, §3), o do “acesso equitativo” (art. 2, §7) e o “princípio da abertura e do equilíbrio” (art. 2, §8). Quanto às medidas, a equalização das comunicabilidades das culturas está vinculada às referências especiais que a Convenção faz às coletividades menos comunicáveis (UNESCO, 2007, p. 29): notadamente, as mulheres (art. 7, §1, a), as minorias culturais (art. 2, §3; art. 7, §1, a) e, de forma geral, os “países em desenvolvimento” (art. 1, f, i; art. 2, §4; art. 14). Conjugados tais medidas e princípios, é possível interpretá-los à luz do enfoque sistêmico adotado.

O reconhecimento da igual dignidade de todas as culturas pode ser entendido como primeiro passo para o reconhecimento, ao lado dos direitos humanos fundamentais culturais individuais e coletivos, de direitos institucionais referidos ao próprio âmbito cultural. Essa perspectiva institucional dos direitos humanos fundamentais tem sido elaborada por Teubner em diversos trabalhos. Enquanto Teubner e Fischer-Lescano (2008, p. 30-45) referem-se a "direitos transindividuais" e ao “conhecimento tradicional como destinatário institucional de direitos fundamentais”, Graber e Teubner (1998, p. 65-66) entendem que

[o]s direitos constitucionais não protegem apenas interesses individuais, mas também bens coletivos, como a liberdade de imprensa, o discurso político livre e outros. Uma perspectiva institucional poderia, entretanto, não somente ver direitos básicos individuais como instrumentos para a proteção de bens coletivos, mas definir as instituições sociais mesmas como o sujeito dos direitos constitucionais e traduzir isso em requisitos procedimentais. [...] Essa não é uma visão coletivista que identifica instituições sociais e coletivas como titulares originárias dos direitos constitucionais e vê indivíduos como um mero instrumento em função dessas coletividades. Pelo contrário, os dois direitos fundamentais constitucionais, o direito à liberdade individual e o direito à dignidade pessoal são as principais garantias para a esfera individual de ação fora das grandes coletividades, [garantias] dirigidas particularmente contra organizações de larga escala.

Teubner e Fischer-Lescano (2008, p. 27) entendem que os direitos humanos fundamentais são "contrainstituições sociais" que restringem a expansividade dos subsistemas sociais "a partir de dentro": "Do ponto de vista da teoria dos sistemas, o papel histórico dos direitos básicos não se exaure em proteger posições legais individuais, mas primariamente consiste em assegurar a autonomia das esferas sociais contra tendências de usurpá-las”. A Convenção da UNESCO, ao conferir uma “dignidade” às diversas comunidades culturais, está se referindo a uma dimensão coletiva; um passo além, porém, já seria um reconhecimento de direitos referidos à própria esfera cultural, como "instituição social”.

Ao lado da proteção da diferenciação do âmbito da cultura em relação aos demais âmbitos comunicacionais e sistemas funcionais da sociedade, fortalecida por uma visão institucional da proteção dos direitos humanos, a referência interna à cultura, pelos direitos individuais e coletivos, 
funda expectativas normativas de equalização das comunicabilidades individuais e coletivas. Tal equalização, interpretada à luz da Convenção da UNESCO sob análise, significaria, sobretudo, a possibilidade de as diversas culturas (comunidades culturais) sobreviverem e expandirem sua comunicabilidade, reforçando intercâmbios (multilaterais) com outras culturas; assim é que se preveem medidas que vão desde a proteção especial e urgente de culturas tradicionais em risco de extinção até a promoção da cooperação tecnológica e o acesso a financiamento por parte das indústrias culturais dos "países em desenvolvimento".

A expectativa normativa, nesse sentido, foca as culturas hoje unilateralmente invadidas por culturas dominantes ou altamente comunicáveis, cuja alta capacidade de difusão decorre de uma vinculação forte ao sistema dos meios de comunicação de massa - em relação aos quais a Convenção também dirige expectativas de pluralização do conteúdo no art. 6. A expectativa é de que as culturas hegemônicas tenham capacidade de contribuir ao lado daquelas hoje menos comunicáveis para a constituição de - e o acesso a - uma cultura global cosmopolita; para tanto, a preservação das condições de criação das manifestações culturais de uma dada comunidade cultural precisa ser conjugada ao acesso aos meios de difusão de sua cultura.

Assim, quando a Convenção destaca o "princípio do acesso equitativo” e o "princípio da abertura e do equilíbrio”, dirige expectativas não no sentido de que cada comunidade cultural possa isolar-se em sua própria criação cultural, autarquicamente, mas de que os diversos segmentos da sociedade mundial possam desenvolver-se a partir de si mesmos (o que, no plano nacional, é expresso pela reiteração, na Convenção, do “princípio da soberania” dos Estados na definição de suas políticas culturais), difundindo dentro da própria comunidade cultural suas expressões culturais e comunicando-as para as demais comunidades, de modo que cada cidadão tenha um acesso equilibrado à pluralidade cultural global, o que é vinculado aos próprios valores do sistema internacional universal (art. 1, c).

Postula-se um autodesenvolvimento de cada comunidade cultural que lhe permita manter (as condições a) a produção de suas manifestações culturais e o acesso a uma grande variedade de culturas "estrangeiras” que possam se incorporar construtivamente (“antropofagicamente”) àquela comunidade.

Daí a ideia de interculturalidade como fundamento de intercâmbios multilaterais no âmbito cultural: “'Interculturalidade’ refere-se à existência e interação equitativa de diversas culturas, assim como à possibilidade de geração de expressões culturais compartilhadas por meio do diálogo e respeito mútuo” (art. 4, §8). Assim, coordenando-se à ideia de interculturalidade, o entendimento de que a prestação dos direitos humanos à sociedade é a promoção e manutenção de sua 
diferenciação funcional (“manutenção de uma ordem diferenciada”) poderia ser complementado se na noção de “ordem diferenciada” se inserir também a dimensão segmentária (soberania nacional, autonomia dos povos, autodeterminação das comunidades culturais).

Desse modo, os direitos humanos, os culturais notadamente, serviriam também à manutenção de uma segmentação adequada à sociedade moderna, complexa e funcionalmente diferenciada; uma segmentação não absoluta, mas propiciadora da própria diferenciação que possibilita o contato (intercultural). Quanto a outros princípios de diferenciação (na forma hierárquica ou de centro-periferia), os direitos humanos, inclusive culturais, também funcionariam para mantê-los de alguma forma, porém coordenando-os com a diferenciação funcional e condicionando-os (limitando-os) a certos espaços (organizações, comunidades organizadas hierarquicamente, etc.).

Destaca-se que, no âmbito cultural, não existe apenas uma diferença de tempos, mas também uma diferença de espaços - culturas diversas que coexistem hoje, cada qual tendo legítimas pretensões não só de sobrevivência, mas de (continuar a) desenvolver-se vivamente. Essas pretensões devem ser reconhecidas como expectativas normativas de autodesenvolvimento de uma cultura, ao lado das outras e com as outras.

Busca-se proteger as culturas não como foto acabada, mas como filme vivo, em desenvolvimento, em uma própria evolução interna, com interferências ou irritações externas. Só assim é possível o diálogo intercultural, com a garantia da “autonomia procedimental” das culturas (TEUBNER; FISCHER-LESCANO, 2008, p. 41), que devem poder decidir como e quando interagir entre si.

Não há, portanto, que se postular uma analogia entre biodiversidade e diversidade cultural se esta implicar uma “culturalização” da "evolução das espécies”, como concebe Amartya Sen (2000, p. 276-277):

No caso da cultura, porém, as tradições perdidas podem fazer muita falta. A extinção de antigos modos de vida pode causar angústia e um profundo senso de perda. É um pouco como a extinção de espécies animais mais antigas. A eliminação de velhas espécies em favor de espécies "mais aptas” com condições “melhores” para sobreviver e multiplicar-se pode ser lamentada, e o fato de as novas espécies serem "melhores" no sistema de comparação darwiniano não necessariamente será visto como suficientemente consolador.

\section{OS DIREITOS HUMANOS CULTURAIS E OS SISTEMAS INTERNACIONAIS DE DIREITOS HUMANOS}

No que diz respeito a uma perspectiva mais abrangente da inserção dos direitos culturais no sistema internacional universal de direitos humanos, centrado na Organização das Nações 
Unidas (ONU), nota-se que a ausência de uma instância jurisdicional que abarque em sua competência a matéria dos direitos humanos - que só é tratada, restrita e reflexamente, na Corte Internacional de Justiça e no Tribunal Penal Internacional - torna a implementação dos direitos humanos uma tarefa monitorada por instâncias administrativas (comitês) com atribuições técnicas, mas suscetíveis ao sistema político, já que não há razoável executoriedade (enforcement) jurídica de suas decisões para além de uma "sanção reputacional" da "comunidade internacional" (PIOVESAN, 2011, p. 177-178).

Nesse sentido, continua a haver uma seletividade política a acobertar os Estados de melhor posicionamento nos sistemas econômico e político - como aqueles pertencentes ao Conselho de Segurança da ONU, notadamente os Estados Unidos. Por um lado, os Estados Unidos têm uma postura altamente restritiva aos direitos humanos que não se definam em uma semântica estritamente liberal-clássica; embora essa seja a interpretação da Constituição estadunidense adotada por sua Suprema Corte, também no plano do direito internacional não há grandes esforços por reconhecer direitos humanos além daqueles tradicionalmente classificados como "civis e políticos”.

Restringindo os direitos humanos praticamente ao direito de voto e às liberdades públicas, mesmo assim há consentimento com graves violações internas desses direitos, como os notórios casos da pena de morte em alguns estados e da prisão de Guantánamo. Por outro lado, os EUA fazem um uso ideológico e estratégico ou instrumental dos direitos humanos quando se trata de justificar violações da ordem jurídica internacional e de ordens jurídicas estrangeiras por interesses políticos e econômicos do país.

Assim, os direitos humanos acabam flexibilizando-se como uma semântica marginal ao sistema jurídico e aplicável conforme códigos e programas econômicos e políticos. No plano funcional, verifica-se tal corrupção sistêmica; no plano da segmentação da sociedade mundial em países, verifica-se um “imperialismo dos direitos humanos” (NEVES, 2007a, p. 432-437) por parte dos países melhor posicionados nos sistemas funcionais político (e.g., membros permanentes do Conselho de Segurança) e econômico (controladores de grandes fluxos de bens e serviços de alto valor agregado para todo o mundo).

Verificando-se alta conversibilidade dos meios (ter, poder, etc.) detidos pelos países quando atuam no plano internacional, aqui ganha imenso relevo a postura dos Estados Unidos em sua defesa de um minimalismo de direitos humanos e de uma maximização da liberalização econômica; exemplificativamente, Wouters e De Meester (2008, p. 207, nota 10) registram que os EUA preferiam uma versão da Convenção da UNESCO que “deixasse abertas opções mais fracas 
de obrigações”.

Já na análise dos sistemas internacionais regionais de direitos humanos, salta aos olhos, nos sistemas europeu e interamericano, a bipartição efetiva dos regimes de tratamento dos "direitos civis e políticos” e dos “direitos sociais, econômicos e culturais”, enquanto se afirma, quase que retoricamente, a indivisibilidade dessas categorias (como na Conferência de Viena de 1993). À primeira categoria se concede a judicialização, com acesso direto dos indivíduos à corte no caso europeu; ainda assim, a vinculatoriedade e a executoriedade (enforcement) jurídicas das sentenças não são suficientes para dispensar um “constrangimento” político que dê eficácia a tais decisões. Já quanto aos "direitos sociais, econômicos e culturais", os tratados tornam-se quase soft law, e o monitoramento da "realização progressiva” desses direitos pelos órgãos não judiciais (Comitê Europeu dos Direitos Sociais e Comissão Interamericana de Direitos Humanos) inevitavelmente reduz a juridicidade e a efetividade do mecanismo.

A diferenciação entre ambas as classes de direitos ainda é apoiada pela doutrina jurídica predominante, notadamente com base no argumento que vincula direitos civis e políticos à omissão estatal e direitos sociais, econômicos e culturais à ação estatal e, portanto, a custos - argumento este que não procede, uma vez que se considerem os custos das prestações legislativas e administrativas destinadas a efetivar, por exemplo, o Estado democrático de Direito e os direitos políticos (e.g., o custo das eleições) e o “direito humano civil” de liberdade econômica (e.g., o custo das instituições estatais como as agências reguladoras e as instituições voltadas ao mercado financeiro).

Em termos dos sistemas internacionais de proteção aos direitos humanos (tratados internacionais e respectivas instituições), universais e regionais, a bipartição parece ter um duplo fundamento, antes político que jurídico: trata-se de uma bipartição que remonta a ideologias (políticas), antes que a diferenças estruturais dos direitos; a bipartição, consequentemente, pretende facilitar a negociação política e maximizar as possibilidades de consenso, permitindo que Estados que adotem quase que exclusivamente uma daquelas concepções “puras” de ideologia (direitos liberais versus direitos sociais) possam se tornar parte de pelo menos um dos acordos - em regra, têm vantagem os direitos civis e políticos.

A referida dicotomia entre as categorias de direitos humanos (e também a classificação das demais categorias, como a de direitos difusos) é também solapada por um uso estratégico dessa bipartição pelas organizações não governamentais (ONGs) que atuam na defesa dos direitos humanos perante cortes internacionais: como propõe Abramovich (2004), quando apenas há tutela jurisdicional para “direitos civis e políticos”, é possível buscar a satisfação de “direitos sociais, econômicos e culturais” indiretamente, por um apelo àqueles, notadamente inserindo-se no 
conteúdo daqueles correspondentes deveres de prestações positivas que se colocam como condição de possibilidade de seu pleno gozo.

Piovesan (2011, p. 154) relata que, para se chegar à Corte Interamericana, cuja competência material é circunscrita à Convenção Americana de Direitos Humanos - a qual apresenta conteúdo que abarca apenas direitos civis e políticos -, já houve argumentações (vencedoras) que invocaram violação de direitos civis e políticos, como o direito de reunião e associação, para proteger direitos trabalhistas, bem como que invocaram violação ao direito de propriedade privada para a cobrança de valores garantidos por direitos de seguridade social. Assim, por exemplo, a Corte Interamericana reconheceu que o direito humano à vida, típico “direito civil”, implica não apenas deveres de omissão do Estado, mas também “medidas positivas apropriadas para proteger o direito à vida digna [...]” (Piovesan, 2011, p. 152).

Alguns direitos culturais (no sentido próprio de direitos referidos ao âmbito cultural) são inseridos na categoria dos “direitos civis e políticos” e, então, gozam de tutela jurisdicional internacional. Pense-se, ilustrativamente, na liberdade de expressão. Porém, ainda assim há graves obstáculos nos sistemas internacionais regionais. No caso (inter)americano, a falta de acesso direto dos indivíduos à Corte levou historicamente a alguma obstaculização política (seletividade) de certos casos - notando-se aí certa desdiferenciação do direito pela política, embora Piovesan (2011, p. 135) ressalte que tal fenômeno foi atenuado por reforma do regulamento da Comissão em 2001.

Quanto ao sistema africano, embora se note o tratamento das duas referidas categorias de direitos humanos em um mesmo instrumento (a Carta Africana dos Direitos Humanos e dos Povos), bem como um enfoque de direitos coletivos, presumivelmente adequado à respectiva realidade, destaca-se a fragilidade institucional do sistema e sua dependência política. Essa dependência também parece ocorrer no sistema europeu, mas aí há maior atuação do sistema jurídico, i.e., maior estabilização contrafática de expectativas normativas, já que os Estados pertencentes a este sistema problematizam em alto grau o descumprimento de decisões da Corte e da Comissão Europeia de Direitos Humanos.

Na África, porém, não há grande comunicabilidade, nem jurídica nem política, das decisões da Comissão. Por outro lado, tanto no sistema africano quanto no (inter)americano, a facultatividade do Estado-parte da Carta ou Convenção de Direitos Humanos em submeter-se à jurisdição da respectiva Corte enfraquece o sistema. Como já destacado, a ilegitimidade ativa de grupos, indivíduos e organizações não governamentais perante a Corte Americana dos Direitos Humanos ainda se manifesta como uma restrição muitas vezes política sobre a juridicidade dos direitos garantidos e do sistema institucional que os garante. 
Entretanto, no sistema africano, a excepcionalidade da legitimação ativa de particulares perante a Corte Africana dos Direitos Humanos e dos Povos torna ainda mais patente a desdiferenciação política do direito, ao exigir aceitação específica, pelo Estado a ser denunciado, da possibilidade de ser denunciado por indivíduos ou ONGs. Dessa forma, o Estado pode se beneficiar simbolicamente de ser parte da Carta Africana de Direitos Humanos e dos Povos, usar como álibi ${ }^{2}$ sua submissão à jurisdição da respectiva Corte e, ainda assim, não proceder à aceitação da legitimidade ativa de particulares para denunciá-lo.

Dessarte, a análise do direito internacional também permite reforçar a crítica à dicotomia entre “direitos civis e políticos” e “direitos sociais, econômicos e culturais”, erodida seja por um entendimento dogmático (estrutura dos direitos), seja pela prática judicial, na qual o direito de uma categoria pode ser indiretamente tutelado pela invocação de um direito de outra categoria - muitas vezes com uma ampliação hermeneuticamente abusiva dos "programas" e "âmbitos normativos" (cf. MÜLLER, 2009, p. 244-268).

Essa dicotomia, ambivalentemente reforçada e desiludida pelos próprios textos normativos internacionais de direitos humanos, que reafirmam ambas as classes de direitos para em seguida proclamar a "indivisibilidade dos direitos humanos", chega ao ponto de poder ser apontada como um bloqueio político ao direito. Apesar de se entender a constituição como um acoplamento estrutural entre política e direito - entendimento que, mutatis mutandis, pode ser estendido aos tratados internacionais de direitos humanos - pode-se entender que a atual divisão das categorias de direitos humanos é um impacto desdiferenciante da política sobre o direito. Os direitos culturais, por serem um ponto cego na diferenciação entre direitos civis e direitos sociais, revelam-no com acuidade.

Isso se configura na medida em que a prática jurídica revela uma mútua implicação entre manipulação instrumental das categorias (tutelar o direito de uma espécie pela invocação de um direito de outra espécie, que possa abarcar aquele - cujo âmbito revestiria melhor a situação sob julgamento), e possibilidade de judicialização dos direitos de uma categoria e negação dessa possibilidade aos direitos da outra classe.

Ainda, na perspectiva das estruturas das normas, parece ser evidente o reconhecimento de que os direitos de ambas as categorias implicam tanto ações quanto omissões por parte do Estado, o que, ao lado do fato de que uma omissão também pode implicar custos (e.g., para a criação de

\footnotetext{
${ }^{2}$ Neves (2007b, p. 37-39) aponta a ideia de "legislação-álibi” como uma forma pela qual "o legislador procura descarregar-se de pressões políticas ou apresentar o Estado como sensível às exigências e expectativas dos cidadãos [...]. A legislação-álibi decorre da tentativa de dar a aparência de uma solução dos respectivos problemas sociais ou, no mínimo, da pretensão de convencer o público das boas intenções do legislador. Como se tem observado, ela não apenas deixa os problemas sem solução, mas além disso obstrui o caminho para que eles sejam resolvidos”.
} 
instituições e estruturas de contenção, como na área da segurança pública), retira as bases do reconhecimento de diferentes “juridicidades" para cada categoria (e.g., programaticidade dos direitos sociais versus eficácia plena dos direitos civis e políticos) (ABRAMOVICH, 2004; HOLMES; SUNSTEIN, 1999; SILVA, 2010).

Pelo lado da política, sim, parece haver justificativas mais plausíveis para a bipartição das categorias de direitos fundamentais - além dessas duas categorias, os direitos difusos, direitos da humanidade, etc. parecem ser subsumidos às mesmas dificuldades de realização pressupostas para os direitos sociais.

No plano político, destaca-se primeiro um discurso sobre o custo dos direitos sociais contraposto à natural realização dos direitos civis e políticos, assim como se pode constatar algo como uma instrumentalização política da constituição e dos direitos humanos.

Ao lado disso, está o fenômeno histórico e político-ideológico que fundamentou a bipartição dos direitos humanos e ainda traz dificuldades à formação de um consenso internacional amplo sobre instrumentos que consagrem as várias categorias de direitos humanos - dividindo-as, ainda que artificialmente, as chances de consenso são potencializadas e podem-se aprovar textos normativos separados, como ocorreu com os Pactos Internacionais de 1966.

\section{CULTURA VERSUS PROPRIEDADE INTELECTUAL}

Interessantes relações intersistêmicas são visualizáveis também entre economia e direito, particularmente no interior do próprio direito internacional, nos diferentes programas normativos do direito do comércio internacional e do direito da propriedade intelectual, de um lado, e do direito internacional dos direitos humanos (particularmente, dos direitos humanos culturais) de outro. Os entrelaçamentos entre esses ramos (e.g., a propriedade intelectual é também considerada um direito humano, bem como a liberdade econômica) nem sempre são claramente pré-programados no interior do sistema jurídico, mas as colisões implícitas e expressas não deixam de ser frequentes.

Em primeiro lugar, é possível apontar um conflito intrajurídico que se desenha nas tensões entre a "agressivamente propagada expansão global dos direitos de propriedade intelectual, de um lado, e a manutenção da diversidade cultural e da biodiversidade, de outro lado” (TEUBNER; FISCHER-LESCANO, 2008, p. 20). De um lado, a hard law da propriedade intelectual traduz o problema da proteção dos conhecimentos tradicionais (e.g., cultura oral indígena) em uma semântica jurídica que requer a "novidade" do conhecimento e, com o cumprimento de outros 
requisitos legais, confere-lhe a tutela segundo a lógica da exclusividade de exploração comercial e da remuneração da exploração desses conhecimentos.

De outro lado, diagnostica-se a falta de um direito vinculante a proteger a própria fonte desses conhecimentos produzidos em segmentos da sociedade suficientemente peculiares em sua lógica de diferenciação social e em seu entendimento da produção e dos usos do saber (TEUBNER; FISCHER-LESCANO, 2008, p. 19). Entre a economia global e a cultura local, verifica-se uma imposição unilateral da lógica daquela sobre esta, com uma desdiferenciação sistêmica (colonização da cultura pela economia) jungida ao que Teubner e Fischer-Lescano (2008, p. 27-34) chamam de “colisão entre formas de diferenciação social” (imperialismo do “moderno” sobre o "tradicional”), o que não deixa de representar também um conflito entre os representantes dessas diferentes racionalidades (portanto, entre segmentos da sociedade mundial).

Trata-se de um conflito entre formas de organização social predominantes em diferentes segmentos da sociedade mundial - se as comunidades indígenas se comunicam de alguma forma relevante com o resto da sociedade, são partes da sociedade mundial, e sua presente situação é resultado também dessa comunicação (cf. LUHMANN, 2007, p. 127).

Na sociedade mundial, continua a ser relevante a segmentação, notadamente a diferença entre países, como fragmentos da sociedade vinculados a um respectivo Estado (organização central do sistema político); i.e., como segmentos regionais da sociedade mundial que permanecem como referência semântica nos diversos âmbitos comunicativos, mesmo no sistema econômico e, notadamente, no âmbito cultural.

Porém, no marco da teoria dos sistemas, a diferenciação funcional seria a forma predominante na atualidade (LUHMANN, 2007, p. 589-615) - embora satisfatoriamente realizada apenas em uma pequena parte da sociedade mundial, que Neves (2008, p. 215-258) identifica como países centrais, em contraposição ao tipo ideal "periférico". Em segmentos da sociedade como as comunidades indígenas, a diferenciação se dá primordialmente por formas que não a funcional - a segmentação em tribos (LUHMANN, 2007, p. 485), por exemplo, bem como a segmentação interna a cada comunidade por critérios hierárquicos (LUHMANN, 2007, p. 522) ou por caracteres naturais de gênero e idade (LUHMANN, 2007, p. 489).

A forma de diferenciação predominante com base na qual um segmento da sociedade mundial se autoconcebe e que guia sua reprodução não deixa também de ser, cognitiva e muitas vezes também normativamente, o ponto de partida para a observação dos outros segmentos. Assim, aos olhos dos segmentos "modernos" que se autorrepresentam como sociedade mundial funcionalmente diferenciada, comunidades indígenas são, sobretudo, funcionalmente 
indiferenciadas - (o equivalente a) a cultura, para estes, cobre mais do que aqueles entendem (para si) como cultura.

O direito internacional reconhece-se em uma transição da diferenciação segmentária (entre territórios) para a diferenciação funcional (divisão de trabalho entre setores especializados) (KOSKENNIEMI, 2006, p. 71), mas, antes do que uma visão evolucionária, os direitos culturais consagram a legitimidade das pretensões de cada segmento de desenvolver-se segundo seus padrões internos, seus próprios recursos, comunicações, referências semânticas; então, a própria coexistência da parcela da sociedade definida como moderna, na qual predomina a diferenciação funcional (ou em que, pelo menos, esta forma é muito relevante), com a parcela da sociedade em que tal forma de diferenciação não é relevante implica a colisão de racionalidades sociais, de formas de diferenciação com as quais tais partes guiam sua autorreferência e sua heterorreferência.

Portanto, no choque entre dois tipos de fragmentação (diferenciação funcional e diferenciação segmentária), não se pode deixar de frisar a transversalidade de outras dimensões de conflito: conflitos segmentários (entre as parcelas da sociedade "representantes" de cada forma de diferenciação), conflitos funcionais intersistêmicos (e.g., economia versus cultura) e conflitos funcionais intrassistêmicos (diferentes concepções de cultura, de economia, de política).

\begin{abstract}
De forma altamente simplificada, isso significa: quando usam o conhecimento tradicional, interesses relacionados de utilização econômica, científica, artística, midiática e médica colidem com reivindicações pela integridade e diversidade de culturas, religiões e formas de vida. [...] [O] termo "racionalidades colidentes" não descreve adequadamente o problema do conhecimento tradicional, já que faz justiça apenas à simples, mas não à dupla fragmentação na sociedade global. Embora esclareça como estoques de conhecimento tradicional são submetidos a demandas divergentes de regimes funcionais globais, não considera o segundo nível de fragmentação - o policentrismo cultural, o conflito entre várias culturas do mundo. No entanto, o conflito do conhecimento tradicional emerge precisamente desta dupla fragmentação dos sistemas funcionais globais, de um lado, e das culturas regionais na sociedade global, de outro. (TEUBNER; FISCHER-LESCANO, 2008, p. 22-23, grifos dos autores)
\end{abstract}

$\mathrm{Na}$ verdade, ao lado de comunidades indígenas, há atores altamente especializados e razoavelmente definíveis - e não a sociedade "moderna” como um todo - que participam dessa colisão que toma uma forma jurídica: centros de pesquisa, organizações não governamentais, grandes empresas transnacionais.

O conflito entre esses dois lados é reconstruído pelo direito da propriedade intelectual por meio da criação e aplicação unilateral de seus programas (textos normativos). Trata-se de regimes “monocontexturais”, que capturam o conhecimento produzido dentro de uma comunidade para a qual a condição (e o resultado) de produção daquele conhecimento é sua integração holística à vida das pessoas daquela comunidade; o conhecimento capturado é então dilacerado pela lógica da 
divisão funcional, minando-se as bases da própria reprodução desse conhecimento (TEUBNER; FISCHER-LESCANO, 2008, p. 23-24).

Teubner e Fischer-Lescano (2008, p. 27) entendem a autocontenção das estruturas “modernas” que cortam transversalmente os diversos sistemas como pressuposto para uma abertura às condições de produção do "conhecimento tradicional” e, portanto, para uma tutela adequada dessa instituição. Essa autocontenção não significa uma resistência genérica à modernidade, mas demandas pontuais e intensivas para que as estruturas econômicas e jurídicas da sociedade moderna funcionalmente diferenciada calibrem seus regimes para respeitarem as culturas que, diante da sociedade mundial, são vistas como regionais ${ }^{3}$.

Nessa (auto)contenção da expansividade dos sistemas funcionais diante das "culturas tradicionais”, alguns elementos fundamentais são sugeridos pelos autores (TEUBNER; FISCHERLESCANO, 2008, p. 28-45). Primeiramente, destaca-se a necessidade de um tratamento da extensão da eficácia dos direitos humanos fundamentais aos agentes privados (como as universidades, museus e corporações econômicas que praticam a biopirataria).

Urge também a previsão, em programas normativos, não só da tutela da integridade cultural, mas também de proibições, invalidades, sanções e compensações que a sustentem, o que não é considerado pela atual normatização internacional dos direitos intelectuais, tampouco pelos textos normativos de direitos humanos. Ainda, é preciso introduzir nos textos normativos internacionais regulações efetivas sobre "consenso prévio informado" e a "divisão dos benefícios”, exigências para o tratamento dos “conhecimentos tradicionais”.

Para fazer frente à "gentil civilização" (cf. KOSKENNIEMI, 2001, p. 70-88) do direito da propriedade intelectual, o direito apenas pode elaborar programas jurídicos igualmente fortes que reconheçam "direitos transindividuais" e tutelem o próprio “conhecimento tradicional” como destinatário institucional de direitos humanos.

Finalmente, reconhecendo que a simples remissão da legislação internacional à normatividade de comunidades "tradicionais" seria improdutiva, pois apenas reproduziria o problema da colisão de lógicas de diferenciação social (diferenciação funcional versus holismo), Teubner e Fischer-Lescano (2008, p. 31, 40-43) visualizam que a proteção de comunidades culturais é possível uma vez que o direito internacional “moderno" reconstrua internamente a realidade (cognitiva) e as pretensões (normativas) dessas comunidades, permanecendo operacionalmente fechado (operando por suas próprias estruturas), mas abrindo-se cognitivamente

\footnotetext{
${ }^{3}$ Para uma discussão sobre modernidade, cultura e direito a partir da teoria dos sistemas, cf. AMATO, 2015. 
às comunidades (cujas formas jurídicas podem ser excepcionadas pelo direito moderno na forma de reservas de ordem pública).

Às comunidades tradicionais é necessário também reconhecer o direito de autodeterminação para que procedimentalmente sejam inseridas quando os problemas jurídicos lhe digam respeito - o direito de autodeterminação significa que a comunidade pode ser vista institucionalmente como um centro normativo de imputação, com direito de ação e direito a ser ouvida.

Assim, o direito adotaria um caráter "policontextural” - contraposto à atual definição unilateral de um direito "monotextural" - e apenas desse modo se poderia evitar o autoritarismo, obedecendo-se a uma lógica da reciprocidade e da alteridade, que impõe a audiência de todas as partes envolvidas (altera pars audiatur). Note-se que, quando se reconstrói o “direito indígena”, os mais diversos problemas acabam envolvendo um "direito à identidade cultural”4

A tese de Teubner (2012, p. 162-171; TEUBNER; FISCHER-LESCANO, 2008, p. 5-7) sobre a dupla fragmentação da sociedade moderna encontra grandes restrições empíricas no cenário descrito neste trabalho, notadamente quando as pretensões culturais encontram os condicionamentos impostos pela própria autopoiese dos sistemas político e econômico. A proposta do autor, como visto, consiste em que, diante da incomensurabilidade dos valores de cada cultura e de sua mútua opacidade, o máximo que se pode pretender é uma hetero-observação que reconstrua, no âmbito de cada cultura (Teubner destaca a cultura moderna - sociedade funcionalmente diferenciada - em relação às comunidades/culturas tradicionais), a cultura alheia, com os inevitáveis defeitos de tradução que tal processo pode gerar.

No plano jurídico, os direitos humanos culturais contribuiriam para tal diálogo: 1) pela “atribuição de direitos comunais-coletivos” a tais comunidades tradicionais, dada sua concepção essencialmente coletivista de vida; 2) por “direitos de participação”, pelos quais a comunidade toda fosse envolvida nas negociações com organizações representantes do moderno sistema funcional econômico; 3) por “compensação monetária” diante dessas trocas de recursos que as culturas

\footnotetext{
${ }^{4}$ Relata Piovesan (2011, p. 153-154), ao analisar casos julgados pela Corte Interamericana de Direitos Humanos, que esta Corte reconheceu "o direito dos povos indígenas à propriedade coletiva da terra, como uma tradição comunitária, e como um direito fundamental e básico à sua cultura, à sua vida espiritual, à sua integridade e à sua sobrevivência econômica"; que "serviços de saúde [...] devem ser apropriados sob a perspectiva cultural, incluindo cuidados preventivos, práticas curativas e medicinas tradicionais"; que "a terra, para os povos indígenas, não é apenas um meio de subsistência, mas um elemento integrante de sua cosmovisão, de sua religiosidade e de sua identidade cultural. Isso porque a terra estaria estreitamente relacionada com suas tradições e expressões orais, costumes e línguas, artes e rituais, bem como com a sua relação com a natureza, arte culinária, direito consuetudinário... Em virtude de sua relação com a natureza, os membros das comunidades indígenas transmitem de geração para geração este patrimônio cultural imaterial, que é recriado constantemente pelos membros da comunidade indígena. Concluiu a Corte que a identidade cultural é um componente agregado ao próprio direito à vida lato sensu. Desse modo, se é violada a identidade cultural, a própria vida vê-se inevitavelmente violada”.
} 
tradicionais podem fazer com a sociedade (ou a economia, especialmente) “moderna” (TEUBNER, 2012, p. 169-171).

Assim, Teubner acredita que as tendências de diferenciação e racionalização da sociedade moderna (em termos weberianos, tendências ao “cálculo instrumental” e à “organização burocrática”) possam ser contrabalançadas por um constitucionalismo reflexivo, isto é, que faça frente a tal direção da evolução social (VESTING, 2004, p. 31).

Permanece diagnosticada a sugestão de um diálogo das ordens jurídicas institucionalizadas (produzidas segundo a lógica da sociedade complexamente diferenciada) com as ordens locais mais culturalmente distanciadas da sociedade global - notadamente por direitos de participação das comunidades envolvidas nas argumentações e decisões de seu interesse, direitos esses consagrados pelas ordens jurídicas mais formalizadas e estruturadas (nacionais, inter, trans e supranacionais), que então poderão reconstruir, ainda que com pontos de intraduzibilidade, as pretensões (e o contexto cultural a elas subjacente) das diversas partes interessadas - as comunidades autóctones, especialmente (TEUBNER, 2012, p. 162-171; NEVES, 2009, p. 216-229).

A presença da cultura nos sistemas internacionais de direitos humanos e na ordem jurídica da economia mundial aponta limites empíricos da pretensão normativa desse projeto de constitucionalismo para além e aquém do Estado nacional.

\section{CULTURA E COMÉRCIO - OU UNESCO VERSUS OMC}

A mesma lógica de alteridade e um possível acoplamento estrutural (entre cultura e economia) procedimentalmente operacionalizado são demandas observadas em análises sobre o direito humano à cultura e o direito do comércio internacional - especificamente, são pontos que se depreendem de estudos acerca da Convenção da UNESCO sobre a Proteção e Promoção da Diversidade das Expressões Culturais em suas (possíveis) relações com a normatividade da Organização Mundial do Comércio (OMC). Cabe destacar que a tematização da relação entre livrecomércio e direitos humanos é cooriginária ao estabelecimento da OMC em 1994 e que “[o] relacionamento entre direitos humanos em geral e liberalização do comércio foi colocado na agenda principalmente por ONGs” (BREINING-KAUFMANN, 2005, p. 114).

Particularmente quanto às relações entre a Convenção sobre Diversidade Cultural e a OMC, deve-se notar que a Convenção da UNESCO de 2005 adota uma perspectiva problemática quando autorregula seu potencial conflito com outros textos normativos. Em primeiro lugar, compartilha com outros textos normativos anteriores celebrados no âmbito dessa mesma 
organização um ambivalente entendimento com relação aos direitos humanos: por um lado, pode ser interpretada como um tratado de direitos humanos culturais, inserindo a cultura como espécie dessa categoria de direitos; por outro, parece expressar-se como simples texto normativo sobre cultura ou sobre direitos culturais (sem o status de direitos humanos), submetido portanto à superioridade normativa dos tratados de direitos humanos.

De fato, a definição do que seja um tratado de direitos humanos é problemática, a começar por uma espécie de metonímia (se uma parte do tratado traz cláusulas que podem ser classificadas como “de direitos humanos", todo o tratado pode ser assim classificado?) e a prosseguir por questões de fundamentação normativa (se um tratado concebe como fundamento certo direito humano - a liberdade econômica, por exemplo - seria um tratado de direitos humanos por isso apenas? E apenas por não haver tal referência explícita a um direito humano que o fundamentasse, deixaria de ser um “tratado de direitos humanos”? Dada a amplitude da reconstrução jurídica da sociedade operada pelo direito em seus programas de direitos humanos, haveria tratado que não fosse "de direitos humanos”?). De qualquer modo, o tratamento da cultura pela normatividade da UNESCO não esclarece quaisquer dessas questões.

Se, em seu preâmbulo, a Convenção invoca como uma de suas bases normativas a Declaração Universal dos Direitos Humanos - que reconhece direitos humanos culturais ou um direito humano à cultura -, paradoxalmente parece entender a cultura apenas como pressuposto para a realização dos direitos humanos, mas não como um direito humano em $\mathrm{si}^{5}$. Ao mesmo tempo, ao excluir a cultura do âmbito dos direitos humanos - ou melhor, deixar de incluí-la nesse programa jurídico -, a Convenção nega uma análise caso a caso das colisões entre direitos humanos nos quais um deles seja um direito humano cultural e parece preveni-la por um "sopesamento” antecipado, no qual a cultura nunca predominará (nem parcialmente) sobre qualquer direito humano com o qual conflite em uma situação concreta específica ${ }^{6}$.

Finalmente, apesar de poder ser inserida no marco dos direitos humanos culturais e de

\footnotetext{
${ }^{5}$ Convenção sobre a Proteção e Promoção da Diversidade das Expressões Culturais, preâmbulo: “Celebrando a importância da diversidade cultural para a plena realização dos direitos humanos e das liberdades fundamentais proclamados na Declaração Universal dos Direitos do Homem e outros instrumentos universalmente reconhecidos [...].”

${ }^{6}$ Convenção sobre a Proteção e Promoção da Diversidade das Expressões Culturais, Artigo 2: "Princípios diretores [...] 1. Princípio do respeito aos direitos humanos e às liberdades fundamentais [...] A diversidade cultural somente poderá ser protegida e promovida se estiverem garantidos os direitos humanos e as liberdades fundamentais, tais como a liberdade de expressão, informação e comunicação, bem como a possibilidade dos indivíduos de escolherem expressões culturais. Ninguém poderá invocar as disposições da presente Convenção para atentar contra os direitos do homem e as liberdades fundamentais consagrados na Declaração Universal dos Direitos Humanos e garantidos pelo direito internacional, ou para limitar o âmbito de sua aplicação”. A UNESCO (2007, p. 25) entende que “[a]ssim o risco do relativismo cultural, que em nome da diversidade reconheceria práticas culturais hostis aos princípios fundamentais dos direitos humanos, foi eliminado”.
} 
definir seu relacionamento com outros tratados internacionais como relações de "apoio mútuo, complementaridade e não subordinação” (art. 20, §1), a Convenção acaba autorizando uma subordinação de seu texto a todos os demais tratados; há paridade com estes, mas, simultaneamente: “Nada na presente Convenção será interpretado como modificando os direitos e obrigações das Partes decorrentes de outros tratados dos quais sejam parte” (art. 20, §2).

Portanto, apesar de se considerar como um contraponto à globalização meramente econômica e como uma tentativa de "humanizá-la” (UNESCO, 2007, p. 23-24) - ideia que marca a própria emergência do conceito de "diversidade cultural” (GRABER, 2006, p. 553-554) -, a Convenção não autofundamenta uma juridicidade capaz de fazer frente, por exemplo, ao direito do comércio internacional (HAHN, 2006, p. 540-546). Assim, a Convenção da UNESCO deixou em aberto em que medida "pode prover um 'porto seguro' às políticas culturais que distorçam o comércio e aliviar as tensões que existem na OMC nessa matéria” (WOUTERS; DE MEESTER, 2008, p. 207, nota 11).

Curiosamente, antes mesmo que um expansionismo da economia sobre a cultura, reconstruídos pelo direito internacional - mas sem excluir tal fenômeno -, parece existir uma autocontenção extremada do âmbito cultural (aqui representado pela Convenção vinculante da UNESCO), ao lado de certa prudência, não muito bem definida, da economia (aqui representada pela normatividade da OMC) em relação aos bens e serviços culturais.

Enquanto a Convenção sobre Diversidade Cultural frisa insistentemente que os bens e serviços culturais têm uma "natureza dúplice” (UNESCO, 2007, p. 22) - um valor econômico, mas também um valor cultural por si só (art. 1, g; art. 4, §4) -, “membros da OMC frequentemente tentam manter esses bens e serviços de fora do processo de liberalização comercial na OMC” (WOUTERS; DE MEESTER, 2006, p. 207).

Essa exclusão era baseada no conceito de “exceção cultural”, usado em negociações no âmbito da OMC, em substituição ao qual se adotou o conceito mais amplo - e economicamente menos impactante a uma visão liberal - de “diversidade cultural” (GRABER, 2006, p. 554-555). Ao final, porém, os acordos da OMC sobre o comércio de bens (GATT - General Agreement on Tariffs and Trade, Acordo Geral sobre Tarifas e Comércio), serviços (GATS - General Agreement on Trade in Services, Acordo Geral sobre Comércio de Serviços) e aspectos do comércio relacionados à propriedade intelectual (TRIPs - Agreement on Trade-Related Intellectual Property Rights, Acordo sobre Aspectos dos Direitos de Propriedade Intelectual Relativos ao Comércio), não contêm “referências a uma específica categoria consistente nos bens e serviços culturais”, contrastando, portanto, com a referência da Convenção da UNESCO à natureza dupla destes produtos 
(WOUTERS; DE MEESTER, 2008, p. 216).

Várias medidas, propostas antes mesmo da Convenção sobre Diversidade Cultural (cf. FOOTER; GRABER, 2000, p. 143-144), poderiam ter sido adotadas na normatividade da OMC, mas a relação entre cultura e comércio parece ter revelado por parte da OMC uma escolha pela segunda opção, entre as condutas de "protagonismo histórico” ou de “obscuridade programada” (cf. COSTA, 2009, p. 394).

Por outro lado, foi excluída do texto final da Convenção da UNESCO uma referência contra a pirataria e o enforcement seletivo dos direitos de propriedade intelectual (mais especificamente, dos direitos patrimoniais relacionados à cópia de material protegido por PI propriedade intelectual) pelos Estados (WOUTERS; DE MEESTER, 2008, p. 217).

De qualquer forma, parece haver uma divisão de posturas: os Estados Unidos, olhando com ressalvas instrumentos normativos vinculantes de direitos humanos (inclusive aqueles especificamente relacionados à cultura) que possam afetar de alguma forma os fluxos econômicos (WOUTERS; DE MEESTER, 2008, p. 207 [nota 10], 216); os países europeus, reconhecendo que “o grande peso desses acordos [da OMC] e o eficiente sistema de solução de controvérsias da OMC inclinam a balança para um enfoque meramente comercial dos bens e serviços culturais, ignorando seu valioso papel como veículos de expressões culturais diversas” (WOUTERS; DE MEESTER, 2008, p. 215).

Há, portanto, também um conflito intrassistêmico - na economia e na política, entre diversas concepções e políticas econômicas.

Nota-se que a Convenção da UNESCO busca incentivar não somente a cultura que deve por si só ser protegida (o que não é transformado em bens e produtos culturais), mas também a indústria cultural.

Essa indústria mereceu a previsão de medidas especiais por parte da Convenção, o que é justificado por características próprias dos bens e serviços culturais e das indústrias culturais, que inclusive acentuam a diferença entre esses setores nos países “desenvolvidos” e “em desenvolvimento”, fato para o qual a Convenção também atentou (art. 2, §4; art. 4, §§4 e 5; art. 6, §2, c; art. 10, c; art. 14).

Como notam Wouters e De Meester (2008, p. 217-218), quanto às características econômicas dos bens e serviços culturais: em primeiro lugar, os bens e serviços culturais compartilham com a classe dos bens públicos a característica da não rivalidade: o consumo por uma 
pessoa não exclui o simultâneo consumo por outra7; outra característica dos bens culturais refere-se às economias de escala (cf. AREEDA; KAPLOW; EDLIN, 2004, p. 23-25) e ao baixo custo marginal: reproduzir um bem cultural é relativamente barato e os produtores podem recuperar os custos de produção em seus mercados internos, possibilitando que o produto chegue aos mercados para onde foi exportado a um preço até mesmo menor do que o cobrado no mercado onde foi produzido, o que leva ao problema do dumping ${ }^{8}$; como um produto de maior valor agregado e com maiores custos de produção tende a uma qualidade maior em relação aos seus concorrentes, são favorecidas as indústrias (dos países) capazes de fazer altos investimentos na produção até esperar pelo lucro, o que provoca uma oligopolização e uma concentração, nos países “centrais”, das indústrias culturais realmente competitivas - ampliando-se as assimetrias entre os países e limitando-se a diversidade cultural dos bens acessíveis nos diversos mercados (as culturas centrais reforçam sua comunicabilidade) (WOUTERS; DE MEESTER, 2008, p. 217-218).

Outras questões, desde o acesso ao conhecimento até o incentivo à criação cultural, emergem quando se trata do relacionamento entre comércio internacional, propriedade cultural e cultura no ambiente digital (BURRI-NENOVA, 2008, p. 54-62).

Observa-se, ainda, que a tendência dos custos de produção a caírem proporcionalmente ao aumento de escala incentiva a especialização - e não a diversificação - das indústrias culturais. Assim, ao lado de um conflito econômico e cultural internacional (entre países), há um conflito intersistêmico, já que o funcionamento da economia opera em sentido contrário ao da “esfera cultural” (ou às pretensões vinculadas a essa esfera).

Tal conflito, via de regra, tende a uma prevalência do econômico sobre o cultural, inclusive quando reconstruídos juridicamente - no caso, o direito do comércio internacional, que possui maior juridicidade (vinculatoriedade, justiciabilidade, executoriedade), em regra continua prevalecendo sobre os direitos (humanos) culturais. Por isso que, visualizando "falhas de mercado" no caso, Wouters e De Meester (2008, p. 218) reclamam por uma intervenção estatal. Essa intervenção, que pode se desenvolver inclusive no plano internacional - notadamente na negociação de textos normativos internacionais -, tem ainda se demonstrado insuficiente.

\footnotetext{
${ }^{7}$ Ao lado da não rivalidade, que distingue os bens públicos dos bens privados, aqueles se distinguem destes quanto à variável da exclusibilidade - maior ou menor facilidade (traduzida em custos) de se excluir o consumo do bem por outrem. Cf. COOTER; ULEN, 2004, p. 107-108.

${ }^{8}$ Lin (2008, p. 568) explica: "Dumping é geralmente compreendido como a prática de precificar produtos em um mercado estrangeiro abaixo dos preços de venda no mercado doméstico, ou de vender produtos abaixo do custo. O dumping não é proibido per se no direito da OMC. Entretanto, seus membros são autorizados a tomar medidas para proteger sua indústria doméstica dos efeitos danosos do dumping. Tipicamente, uma medida anti-dumping significa uma sobretaxação anti-dumping em produtos beneficiados pelo dumping originários de um determinado país exportador, de forma a trazer seu preço mais próximo ao 'valor normal' ou a remover o dano à indústria doméstica do país importador”.
} 
No caso, entre a normatividade da OMC e a Convenção da UNESCO verificou-se, da análise a partir de uma perspectiva sistêmico-funcional, que economia e cultura evitam programações específicas em temas mais sensíveis, que poderiam proporcionar um acoplamento estrutural mais estreito e bem definido; na ausência deste, surge espaço para impactos desdiferenciantes da economia sobre a cultura.

Ilustrativamente, Wouters e De Meester (2008, p. 240) analisam a perda de oportunidade de se haver formalizado uma vinculação consultiva entre a UNESCO e a OMC no tema do comércio de bens e serviços culturais, o que se poderia entender como a procedimentalização e operacionalização de um acoplamento estrutural entre cultura e economia - e direito -, na forma de seus programas de direitos humanos (culturais) e direito do comércio internacional.

Já Graber (2006, p. 570-571) analisa três possibilidades de vinculação da OMC à Convenção da UNESCO: por meio de uma interpretação evolutiva do direito da OMC, enriquecida pela Convenção sobre Diversidade Cultural; por meio da criação de salvaguardas culturais (medidas de proteção temporária da indústria doméstica diante de importações); por meio de uma previsão expressa da observância da Convenção da UNESCO pela OMC sempre que se observar um conflito entre comércio e cultura.

Finalmente, outra forma de se operacionalizar um acoplamento estrutural congênere seria a inserção de “cláusulas de interesse público” (ao qual se poderia vincular a “diversidade cultural”) na normatividade antidumping, conectando-se cultura e comércio internacional e tornando-o mais sensível às demandas por diversificação cultural, como propõe Lin (2008, p. 577-586); de qualquer forma, o reconhecimento do "interesse público" depende sempre da vontade e do juízo político do país que queira aplicar tal cláusula (LIN, 2008, p. 585).

Nota-se que medidas antidumping são previstas no GATT, mas não no GATS, e que a extensão de tais medidas a serviços culturais seria altamente controversa e improvável (LIN, 2008, p. 570-571). Dificuldade crescente está na diferenciação entre bens e serviços, notadamente quanto a bens e serviços culturais, diferenciação que resulta na aplicação de diferentes regimes normativos no cerne da OMC (LIN, 2008, p. 567).

Ao lado da dificuldade de diferenciação entre bens e serviços culturais, outro problema é a definição de "produto similar", aquele com relação ao qual um país, se fabricar um bem comercialmente intercambiável, pode impor medidas antidumping; tal definição tem seus obstáculos exacerbados no plano da indústria cultural, já que nesta o valor das marcas e a reputação são enormes, causando problemas na definição do “mercado relevante material” (LIN, 2008, p. 571574): caso se considere que o produto concorre com muitos outros, não haverá qualquer problema 
concorrencial; caso se feche demasiadamente a definição in concreto do mercado relevante, considerando, por exemplo, que a marca do produto o faz ter um mercado próprio, sem ter como concorrentes (ainda que potenciais) outros produtos, pode-se estar desconsiderando o real comportamento dos consumidores (que consideram aqueles produtos como concorrentes, intercambiáveis) e deixando-se de punir práticas anticoncorrenciais.

Outras dificuldades para se impor medidas antidumping ante a colocação em risco da diversidade cultural (analogamente ao que se reconhece como "riscos de saúde") estariam relacionadas a uma necessária aferição do conteúdo que precisa haver para se avaliar os produtos culturais, processo demorado que colidiria com a natureza urgente e liminar das medidas antidumping (LIN, 2008, p. 574-577). Todas essas questões ilustram a dificuldade de se alcançar uma tutela efetiva dos bens e serviços culturais, como objetivada pela Convenção da UNESCO.

Por outro lado, há mesmo um (potencial) bloqueio das medidas propostas na Convenção da UNESCO pela normatividade da OMC: ilustrativamente, o complexo regime desta organização “pode desencorajar os membros da OMC de subsidiar suas indústrias culturais” e a cooperação internacional proposta na Convenção por meio de acordos de coprodução e codistribuição pode infringir princípios da OMC, como o da nação mais favorecida, que requer que um país que concede benefícios a produtos importados de certo membro da organização os conceda aos demais (WOUTERS; DE MEESTER, 2008, p. 218, 222-223).

Ainda, as cláusulas de conflito dos textos normativos adotados no âmbito da OMC e da Convenção da UNESCO resultam em que dificilmente esta possa ter uma influência limitadora e conformadora sobre aqueles. Assim como o Órgão de Solução de Controvérsias não pode aceitar a invocação de um tratado não aprovado no âmbito da OMC como justificativa para qualquer desobediência às normas do comércio internacional, a Convenção da UNESCO considera que não altera qualquer obrigação das partes em outros âmbitos.

Ademais, embora os painéis da OMC e o Órgão da Apelação pudessem vir a considerar a Convenção da UNESCO como recurso interpretativo, isso requereria uma aprovação ao menos implícita dessa Convenção por todos os membros da OMC, o que já foi obstado pelos Estados Unidos, ao terem votado contra a Convenção e feito tal desaprovação constar de registros da comissão que tratou da Convenção no âmbito da UNESCO; ainda, um eventual "valor informativo" da Convenção na interpretação das regras e princípios da OMC é improvável e, embora abstratamente se possa considerar a prevalência de tratados de direitos humanos, direitos trabalhistas e meio ambiente sobre normatizações de direito comercial, essa prevalência dificilmente se faz valer no âmbito do sistema de solução de controvérsias da OMC (WOUTERS; 
DE MEESTER, 2008, p. 232-234).

O direito ao qual está vinculado um sistema forte de justiciabilidade e executoriedade é o direito comercial internacional. As condições extremamente superiores de vinculatoriedade e executoriedade desse direito em relação aos direitos humanos (culturais, no caso), ao lado da negação da construção de acoplamentos estruturais entre estes - que representariam juridicamente um acoplamento entre economia e cultura - contribuem para uma tendência desdiferenciante desta por aquela.

A OMC partiu de uma “estrutura organizacional tímida e informal” (COSTA, 2009, p. 217), possibilitada pela alta identificação ideológica de seus membros, e progressivamente buscou, após crises, a solução da juridificação, da legitimação procedimental e do adensamento organizacional que lhe sustentassem a amplitude de escopo e a heterogeneidade crescente dos membros (COSTA, 2009, p. 214-246, 391-402) ${ }^{9}$.

O processo de juridificação, notadamente no direito internacional, pode ser apreendido em três dimensões e respectivos continua: obrigações (de normas expressamente não jurídicas a regras vinculantes, ius cogens), precisão (de princípios vagos a regras precisas e altamente elaboradas), delegação (da diplomacia às organizações e cortes internacionais e à aplicação doméstica) (ABBOTT et al., 2000, p. 404).

De qualquer modo, no caso da OMC, se a juridificação, notadamente pelo reforço do sistema de solução de controvérsias - principalmente do órgão de apelação -, for também uma “estratégia política” de “parecer apolítico” (COSTA, 2009, p. 398), é certo que não se neutralizam as referências culturais dos próprios julgadores (COSTA, 2009, p. 401), que a formação de blocos de poder passa por mediações culturais ${ }^{10}$ e que a OMC tem que abrir-se à "influência de outros atores, como setores empresariais, sindicais e de ativismo ambientalista, os quais vão se mostrando mais influentes com o tempo [...]” (COSTA, 2009, p. 215).

A irritação do direito internacional econômico por outros campos do direito internacional, que expressa juridicamente a irritação da economia por outros sistemas funcionais, ainda tem, entretanto, que se desenvolver pelo fortalecimento jurídico de programas jurídicos como os direitos

\footnotetext{
${ }^{9}$ Para Costa (2009, p. 223-224), “[e]m primeiro lugar, o fortalecimento do SSC [sistema de solução de controvérsias] como uma instância organizacional ajuda a desvincular a percepção da instituição como um mero foro de debates e, ainda mais, como instrumento estadunidense de imposição de políticas. A diplomacia residente em Genebra e a pluralidade de membros de grupos especiais dá, sem dúvida, um ar de maior independência institucional e, por conseguinte, de uma identidade própria, apesar de reduzida”.

${ }^{10}$ Costa (2009, p. 228) comenta: “O que importa mais destacar, entrementes, é que as dificuldades enfrentadas hoje por muitos países em desenvolver laços identitários bem apertados influem sobre as capacidades de ação política internacional concertada, na medida em que as expectativas a respeito da autocontenção necessária para tanto se pulverizam e com estas - considerando que a institucionalização se deve também à presença do espectro dos conflitos buscam-se formas de legitimação mais abstratas para os cursos de ação escolhidos, inclusive mediante a juridificação”.
} 
humanos.

Esse fortalecimento, por um lado, é condição para a autonomia operacional (autopoiese) do próprio direito e de outros sistemas funcionais e âmbitos comunicacionais pelo direito reconstruídos; por outro, é também condição de maior eficácia dos direitos humanos, pela potencialização de irritações específicas dirigidas à economia e ao “direito econômico” por outros campos reconstruídos juridicamente pelos direitos humanos - como o âmbito comunicacional cultural.

Em termos sistêmicos, tal potencialização seletiva de irritações é o que se obtém pelo mecanismo do acoplamento estrutural, ainda muito deficitário nas relações entre economia e cultura, "direito econômico" e "direito cultural”, direito internacional econômico e direito internacional dos direitos humanos - ou mesmo internamente aos programas de direitos humanos, já que também a economia se funda em direitos humanos como a liberdade de iniciativa, típico direito humano "civil"11.

\section{CONCLUSÃO}

O que dada ordem jurídica considera como direitos humanos ou como direitos culturais depende, em grande medida, não apenas do que se consegue remeter à opinião pública, por meio de processos que legitimam as decisões que consagram tais direitos, mas também do que é autorizado pelo sistema econômico.

Se uma obrigação séria de preservação da diversidade cultural for entendida como obstáculo à livre atuação das organizações econômicas, estas forçarão o sistema político a não aprovar tal obrigação, da mesma forma que dificilmente imporão a si mesmas, na forma de uma autoconstitucionalização ou autorregulamentação, obrigações muito rígidas que ainda possam ser lidas apenas como custos e não como vantagens.

Assim é que, tanto nos planos de heteronormação do sistema econômico (predominante nas ordens nacional, internacional e supranacional) quanto nos de autonormação (o direito transnacional “autorregulado”), a economia ainda controla as possibilidades de proteção dos direitos humanos, e dos direitos culturais em especial, seja no plano de sua positivação, seja no plano de sua concretização, mantendo-se inerte quanto à sua autoconstitucionalização ou desautorizando o sistema político a proceder na direção da efetivação de tais direitos.

Enquanto, para o direito econômico e comercial, as irritações da economia sobre o direito

\footnotetext{
${ }^{11}$ Petersmann (2005, p. 39-42) identifica "liberdade individual, diversidade e competição como problemas comuns aos direitos humanos e ao direito comercial”.
} 
parecem ser positivas ${ }^{12}$, o reverso transparece quanto à ação da economia sobre a política e o direito no que concerne a outros âmbitos da sociedade e do sistema jurídico. Para a codificação universalizante da economia, a cultura como campo das diferenças ainda aparece como um obstáculo.

Para a política, embora a cultura contribua para uma generalização simbólica de alta extensão, produz mais dissenso que consenso, o que depende de procedimentos adequados para captar tal pluralidade, idealmente construídos com vistas a não serem obstruídos por ingerências dominantes de outros sistemas, como o econômico.

Importa considerar que a pretensão de manutenção da diferenciação social, que Luhmann considerou própria à funcionalidade dos direitos fundamentais, encontra novos condicionamentos com a estruturação dos direitos humanos na ordem internacional, em paralelo com a aceleração da mundialização do sistema econômico. Embora a emergência da sociedade mundial se afirme como um processo fragmentário, mas permanente, na longa duração da construção da sociedade moderna e de seus sistemas diferenciados funcionalmente, a aceleração deste processo é bem marcada pela estruturação de "sistemas" internacionais de direitos humanos, de livre comércio e de propriedade intelectual.

Esses “sistemas", com suas organizações, doutrinas, procedimentos e programas decisórios, envolvem prestações recíprocas dos sistemas político e jurídico, similarmente ao que ocorre na ordem constitucional interna dos Estados.

As pretensões de "autocontenção" da economia e de “diálogo" entre culturas e entre sistemas não podem desconsiderar que as dificuldades regulatórias da sociedade mundial não cedem a máximas normativas abstratas, mas dependem da pactuação de programas normativos, da vinculação coletiva por decisões, função que só a política pode prover.

A economia não irá se “conter” diante das culturas nem por uma racionalidade intrínseca do mercado mundial e de suas organizações nem pela generalização de valores sem impositividade. Esquadrinhar os programas normativos existentes e possíveis, propor e justificar alternativas institucionais formuladas nesses programas é tarefa do pensamento jurídico. Dentre essas alternativas, encontram-se novas formas de desenho dos direitos humanos e culturais.

\footnotetext{
12 Para Sand (2004, p. 52-53, grifo do autor), “[o] direito 'internacional’ tornou-se internacional, supranacional e transnacional. Comércio, proteção ambiental e direitos humanos são áreas crescentemente reguladas em todos esses níveis. Isso implica que uma variedade de formas de direito, instituições e graus de normas juridicamente vinculantes estão sendo criados. Em algumas instâncias, há coordenação entre os diferentes níveis do direito, em outras não há. Sob alguns tratados, há cortes e outros mecanismos de solução de conflitos, sob outros não os há. No direito comercial, a interdependência dos sistemas jurídico e econômico contribuiu para sanções mais eficientes.”
} 


\section{REFERÊNCIAS}

ABBOTT et al. The concept of legalization. International Organization, Cambridge (MA), vol. 54, n. 3, p. 401-419, 2000.

ABRAMOVICH, Víctor. Linhas de trabalho em direitos econômicos, sociais e culturais: instrumentos e aliados. Tradução de Maria Lucia de Oliveira Marques. Sur, Revista Internacional de Direitos Humanos, São Paulo, vol. 2, n. 2, p. 188-223, 2005.

AMATO, Lucas Fucci. Constitucionalização corporativa: direitos humanos fundamentais, economia e empresa. Curitiba: Juruá, 2014.

- Cultura, modernidade e direito: dificuldades, possibilidades e diálogos a partir de Luhmann. Revista da Faculdade de Direito - Universidade de São Paulo, São Paulo, vol. 110, 2015.

. Os direitos culturais no direito internacional, na União Europeia e no constitucionalismo brasileiro. Mimeo. 2012. Disponível em: <https://goo.gl/7GB7zn>. Acesso em: 21 jan. 2015.

AREEDA, Phillip; KAPLOW, Louis; EDLIN, Aaron. Antitrust analysis: problems, text, and cases. 6. ed. New York: Aspen, 2004.

BREINING-KAUFMANN, Christine. The legal matrix of human rights and trade law: State obligation versus private rights and obligations. In: COTTIER, Thomas; PAUWELYN, Joost; BÜRGI, Elisabeth. Human rights and international trade. Oxford: Oxford University Press, 2005. p. 95-136.

BURRI-NENOVA, Mira. Trade versus culture in the digital environment: an old conflict in need of a new definition. Journal of International Economic Law, Oxford, vol. 12, n. 1, p. 17-62, 2008.

COOTER, Robert; ULEN, Thomas. Law and economics. 4. ed. Boston: Pearson; Addison Wesley, 2004.

COSTA, José Augusto Fontoura. Decidir e julgar: um estudo multidisciplinar sobre a solução de controvérsias na Organização Mundial do Comércio. 2009. Tese (Professor Titular) - Departamento de Direito Internacional e Comparado, Faculdade de Direito, Universidade de São Paulo, São Paulo, 2009.

FOOTER, Mary E.; GRABER, Christoph Beat. Trade liberalization and cultural policy. Journal of International Economic Law, Oxford, vol. 3, n. 1, p. 115-144, 2000.

GRABER, Christoph Beat. The new UNESCO Convention on Cultural Diversity: a counterbalance to the WTO? Journal of International Economic Law, Oxford, vol. 9, n. 3, p. 553-574, 2006.

; TEUBNER, Gunther. Art and money: constitutional rights in the private sphere? Oxford Journal of Legal Studies, Oxford, vol. 18, n. 1, p. 61-73, 1998.

HAHN, Michael. A clash of cultures? The UNESCO Diversity Convention and international trade law. Journal of International Economic Law, Oxford, vol. 9, n. 3, p. 515-552, 2006. 
HOLMES, Stephen; SUNSTEIN, Cass R. The cost of rights: why liberty depends on taxes. New York: W. W. Norton, 1999.

KANT, Immanuel. Fundamentación de la metafísica de las costumbres. Tradução Manuel García Morente. Madrid: Encuentro, 2003.

KOSKENNIEMI, Martti. Fragmentation of International Law: difficulties arising from the diversification and expansion of international law. Report of the Study Group of The International Law Commission. Geneva: International Law Commission, General Assembly, United Nations, 2006.

. The gentle civilizer of nations: the rise and fall of international law, 1870-1960. Cambridge: Cambridge University Press, 2001.

LIN, Tsai-Yu. Exploring the link between trade and cultural protection in the context of antidumping. Journal of World Trade, The Hague, vol. 42, n. 3, p. 563-586, 2008.

LUHMANN, Niklas. I diritti fondamentali come istituzione. Tradução de Stefano Magnolo. Bari: Dedalo, 2002.

. La sociedad de la sociedad. Tradução Javier Torres Nafarrate. México: Herder, 2007.

MÜLLER, Friedrich. Teoria estruturante do direito I. Tradução Peter Naumann e Eurides Avance de Souza. 2. ed. São Paulo: Revista dos Tribunais, 2009.

NEVES, Marcelo. A constitucionalização simbólica. São Paulo: WMF Martins Fontes, 2007b.

. Entre Têmis e Leviatã: uma relação difícil: o Estado Democrático de Direito a partir e além de Luhmann e Habermas. 2. ed. São Paulo: WMF Martins Fontes, 2008.

. The symbolic force of human rights. Philosophy \& Social Criticism, Thousand Oaks, vol. 33, n. 4, p. 411-444, 2007a.

. Transconstitucionalismo. São Paulo: WMF Martins Fontes, 2009.PETERSMANN, ErnstUlrich. Human rights and international trade: defining and connecting the two fields. In: COTTIER, Thomas; PAUWELYN, Joost; BÜRGI, Elisabeth. Human rights and international trade. Oxford: Oxford University Press, 2005. p. 29-94.

PIOVESAN, Flávia. Direitos humanos e justiça internacional: um estudo comparativo dos sistemas regionais europeu, interamericano e africano. 2. ed. São Paulo: Saraiva, 2011.

SAND, Inger-Johanne. Polycontextuality as an alternative to constitutionalism. In: JOERGES, Christian; SAND, Inger-Johanne; TEUBNER, Gunther. Transnational governance and constitutionalism. Oxford: Hart, 2004. p. 41-65.

SEN, Amartya. Desenvolvimento como liberdade. Tradução Laura Teixeira Motta. São Paulo: Companhia das Letras, 2000.

SILVA, Virgílio Afonso da. Direitos fundamentais: conteúdo essencial, restrições e eficácia. 2. ed. 
São Paulo: Malheiros, 2010.

TEUBNER, Gunther; FISCHER-LESCANO, Andreas. Cannibalizing epistemes: will modern law protect traditional cultural expressions? In: GRABER, Christoph; BURRI-NENOVA, Mira (Ed.). Intellectual property and traditional cultural expressions in a digital environment. Cheltenham: Edward Elgar, 2008. p. 17-45.

. The anonymous matrix: human rights violations by "private" transnational actors. The Modern Law Review, Malden, vol. 69, n. 3, p. 327-346, 2006.

UNESCO (Organização das Nações Unidas para a Educação, a Ciência e a Cultura). Dez chaves para entender a Convenção para a Proteção e a Promoção da Diversidade das Expressões Culturais adotada pela 33a Sessão da Conferência Geral da UNESCO em 2005. Brasília. UNESCO, 2007. Disponível em: <http://goo.gl/dGVkBI>. Acesso em: 15 jan. 2012.

VESTING, Thomas. Constitutionalism or legal theory: comments on Gunther Teubner. In: JOERGES, Christian; SAND, Inger-Johanne; TEUBNER, Gunther. Transnational governance and constitutionalism. Oxford: Hart, 2004. p. 29-39.

WOUTERS, Jan; DE MEESTER, Bart. The UNESCO Convention on Cultural Diversity and the WTO law: a case study in fragmentation of international law. Journal of World Trade, The Hague, vol. 42, n. 1, p. 205-240, 2008.

\title{
ECONOMY AND POLITICS OF CULTURAL RIGHTS IN THE INTERNATIONAL ORDER
}

\begin{abstract}
The paper discusses the restrictions imposed by economy and politics to the normative design of cultural rights in the international legal order. The axis of this analysis is the UNESCO Convention on the Protection and Promotion of the Diversity of Cultural Expressions (2005), but we also detach the problematic conditions of the insertion of cultural rights in the universal and regional systems of human rights. Finally, we focus on the status of cultural rights in relation to intellectual property and to the WTO regime. The work follows a line of analysis from systems theory in order to think the relations between law, politics and economy.
\end{abstract}

\section{KEYWORDS}

Cultural rights. Law and culture. Free trade and human rights. 